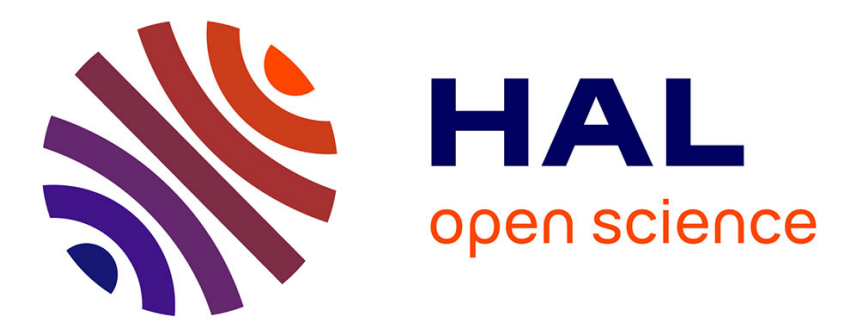

\title{
ITER transfer cask: Preliminary assessment of dose rate due to dust remained in the cask
}

\author{
C. Le Loirec, Y. Peneliau, C. Lacroix, M. Soldaini, D. van Houtte, J. P. \\ Friconneau
}

\section{- To cite this version:}

C. Le Loirec, Y. Peneliau, C. Lacroix, M. Soldaini, D. van Houtte, et al.. ITER transfer cask: Preliminary assessment of dose rate due to dust remained in the cask. Fusion Engineering and Design, 2018, 132, pp.90-98. 10.1016/j.fusengdes.2018.04.027 . cea-02428761

\section{HAL Id: cea-02428761 https://hal-cea.archives-ouvertes.fr/cea-02428761}

Submitted on 6 Jan 2020

HAL is a multi-disciplinary open access archive for the deposit and dissemination of scientific research documents, whether they are published or not. The documents may come from teaching and research institutions in France or abroad, or from public or private research centers.
L'archive ouverte pluridisciplinaire HAL, est destinée au dépôt et à la diffusion de documents scientifiques de niveau recherche, publiés ou non, émanant des établissements d'enseignement et de recherche français ou étrangers, des laboratoires publics ou privés. 


\title{
ITER transfer cask: Preliminary assessment of dose rate due to dust remained in the cask
}

\author{
C. Le Loirec ${ }^{\mathrm{a}, *}$, Y. Peneliau ${ }^{\mathrm{a}}$, C. Lacroix ${ }^{\mathrm{b}}$, M. Soldaini ${ }^{\mathrm{c}}$, D. van Houtte ${ }^{\mathrm{c}}$, J.P. Friconneau ${ }^{\mathrm{d}}$ \\ ${ }^{a}$ CEA, DEN, Cadarache, DER, SPRC, 13108 Saint-Paul-lez-Durance, France \\ b CEA, DEN, Cadarache, DEC, 13108 Saint-Paul-lez-Durance, France \\ ${ }^{\mathrm{c}}$ CEA, DRF, Cadarache, IRFM, 13108 Saint-Paul-lez-Durance, France \\ d ITER Organization, Route de Vinon-sur-Verdon, CS 90 046, 13067 St Paul Lez Durance Cedex, France
}

A R T I C L E IN F O

\section{Keywords:}

Remote handling

Dust

TRIPOLI-4

DARWIN

Dose rate

\begin{abstract}
A B S T R A C T
The Remote Handling tasks scheduled during the ITER maintenance shut-down require transportation of invessel components and remote-handling tools from the Vacuum Vessel (VV) ports to the Hot Cell Building (HCB). These components and tools will be moved using the Cask and Plug Remote Handling System (CPRHS).

During plasma operations, plasma facing components will be highly activated by neutrons and/or contaminated with tritium. After plasma operations, activated dust will be removed from the VV but some amounts will remain. Therefore, the CPRHS may be contaminated by residual activated dust due to the transportation of these components between the VV and the HCB. As the CPRHS is not shielded, residual activated dust may lead to a residual dose rate around the CPRHS.

To assess the risk of external exposition in case of human intervention for maintenance purpose inside or close to the CPRHS, dose rate estimations were performed around and inside the CPRHS for several initial dust configurations with the normalized value of $1 \mathrm{~g}$ of residual activated dust. The results of this study constitute a dosimetric data base and may support ITER Organization in the definition of a decontamination level and maintenance plan.
\end{abstract}

\section{Introduction}

The Remote Handling (RH) tasks scheduled during the ITER maintenance shutdown require transportation of in-vessel components and RH tools from the Vacuum Vessel (VV) ports to the Hot Cell Building (HCB). These components and tools will be moved using the Cask and Plug Remote Handling System (CPRHS). The CPRHS is a vital element in the successful performance of ITER. Its design and development must be planned and executed effectively to ensure the CPRHS is fit for purpose [1].

The CPRHS system comprises the following means [2-4]:

- the cask envelope system (CES) is designed to provide a confinement barrier but no shielding protection is associated with this system,

- the cask transport system (CTS) is designed to provide means for remote transportation and navigation of CES,

- the cask docking station system (CDSS) is designed to provide means to mechanical support and align the CES,

- the in-cask plug handling system (ICPHS) is designed to provide means to guide $\mathrm{RH}$ components during installation and removal.
During plasma operations, plasma facing components such as plugs, will be highly activated by neutrons and/or contaminated with tritium. After plasma operations, activated dust will be removed from the VV but trace amounts will remain. Therefore, the CPRHS, and more specifically the CES, may be contaminated by residual activated dust during the transportation of these components between the $\mathrm{VV}$ and the HCB. Activated dust in the CES can have two sources:

- migration from VV to CPRHS during the docking stage, especially close to the maintenance door,

- transfer from VV components or RH tools on which surfaces dust has adhered.

As the CES is not shielded, residual activated dust lead to a residual dose rate around the CES. In case of failure or incident during the transportation, hands-on operations may be needed to repair the CES, the ICPHS or the CTS. If the CES transports activated components, dose rate levels have already been estimated [5]. But if the CES do not transport any activated components but contain some residual activated dust, no dosimetric estimation has been published nowadays to our

\footnotetext{
* Corresponding author.

E-mail address: Cindy.LELOIREC@cea.fr (C. Le Loirec).
} 
Table 1

Activated dust nuclides important for safety analysis.

\begin{tabular}{ll}
\hline Dust spectrum & Activity $(\mathrm{Bq} / \mathrm{kg})$ at plasma stop \\
\hline $\mathrm{W} 187$ & $8.44 \mathrm{E}+13$ \\
$\mathrm{~W} 185$ & $5.08 \mathrm{E}+12$ \\
$\mathrm{~W} 181$ & $1.98 \mathrm{E}+12$ \\
$\mathrm{R} 186$ & $2.82 \mathrm{E}+11$ \\
$\mathrm{R} 188$ & $9.45 \mathrm{E}+11$ \\
Ta182 & $3.35 \mathrm{E}+10$ \\
Ta186 & $1.55 \mathrm{E}+10$ \\
Ta183 & $7.35 \mathrm{E}+09$ \\
Ta184 & $8.47 \mathrm{E}+09$ \\
Re184 & $1.86 \mathrm{E}+09$ \\
Co60 & $9.61 \mathrm{E}+08$ \\
\hline
\end{tabular}

Table 2

Energy groups recommended for ITER studies and used for gamma spectra determination.

\begin{tabular}{ll}
\hline Energy groups & High energy bound $(\mathrm{MeV})$ \\
\hline 1 & 0.001 \\
2 & 0.01 \\
3 & 0.02 \\
4 & 0.05 \\
5 & 0.10 \\
6 & 0.20 \\
7 & 0.30 \\
8 & 0.40 \\
9 & 0.60 \\
10 & 0.80 \\
11 & 1.00 \\
12 & 1.22 \\
13 & 1.44 \\
14 & 1.66 \\
15 & 2.00 \\
16 & 2.50 \\
17 & 3.00 \\
18 & 4.00 \\
19 & 5.00 \\
20 & 6.50 \\
21 & 8.00 \\
22 & 10.0 \\
24 & 12.0 \\
\hline
\end{tabular}

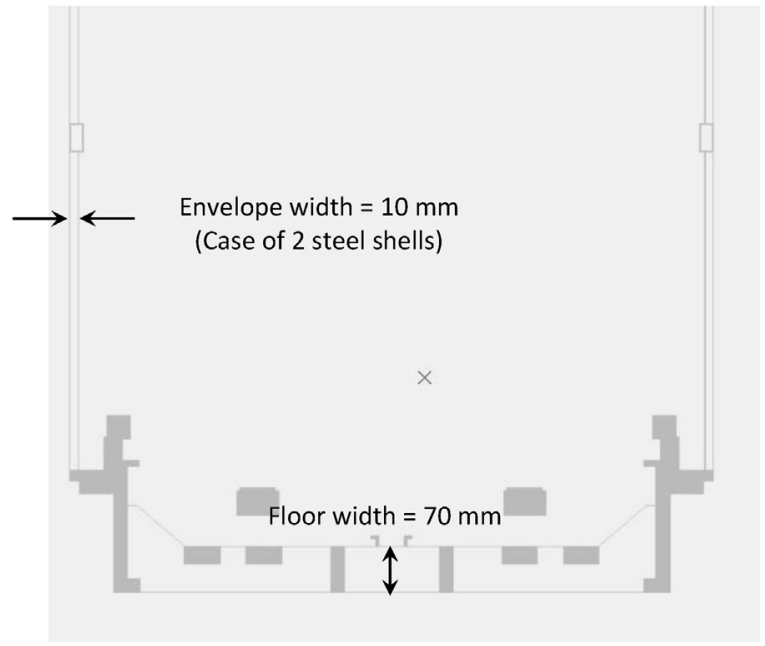

Fig. 2. Final view of the lower part of the CPRHS when two steel shells are taken into account for the envelope.

knowledge.

The objective of this study is to determine the mass of dust allowed in the cask for achieving less than $5 \mu \mathrm{Sv} / \mathrm{h}$ for hands-on operations in and close to the cask. Dose rate estimations around and inside the CES were thus performed in the case of $1 \mathrm{~g}$ of residual activated dust remained in the CES. It is assumed that the workers will be wearing ventilated protective suits against radioactive contamination when working with tritium. The risk of internal exposure is thus limited [6]. In this evaluation we thus only considered the external dose rate from dust. Dose rates were estimated for several configurations representative of possible dust contamination with $1 \mathrm{~g}$ activated dust. Dose rate levels obtained for these configurations constitute a dosimetric data base (DDB) that could be used to estimate the dose rate level due to more complex dust sources obtained by mixing the several configurations defined in this study. This DDB constitutes an helpful tool for ITER Organization in the definition of a decontamination and maintenance plan.

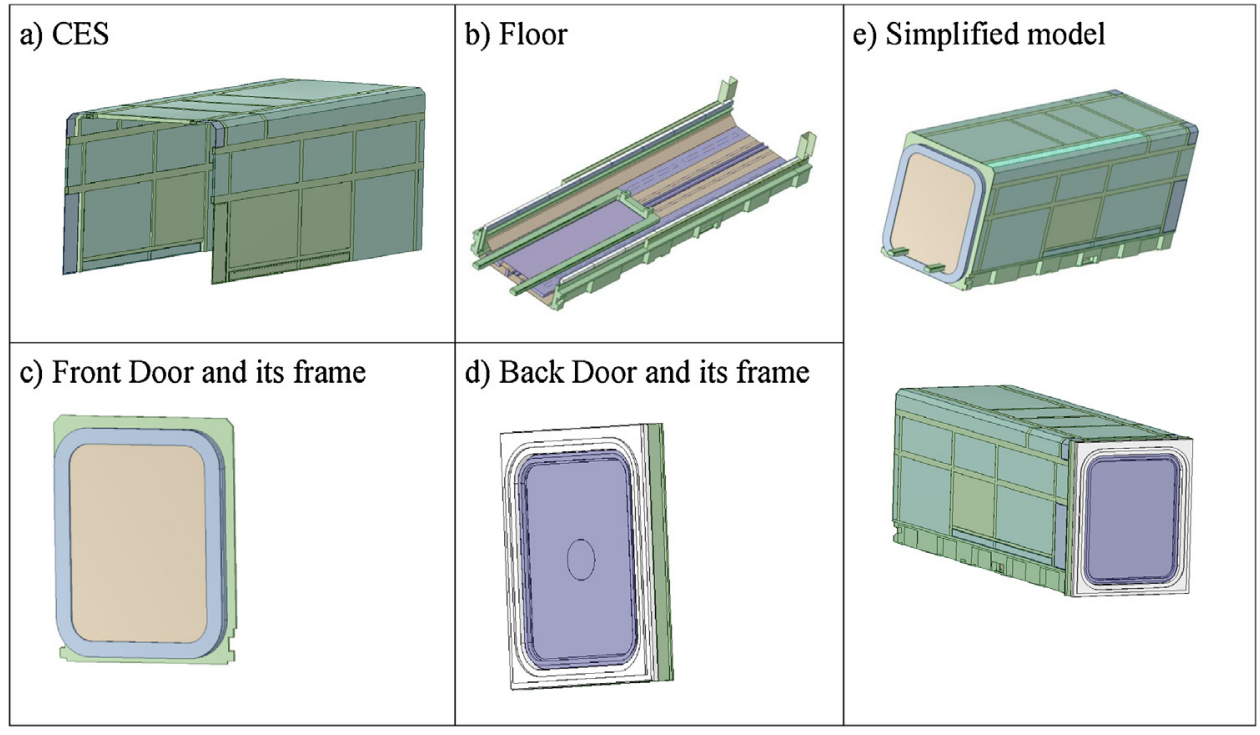

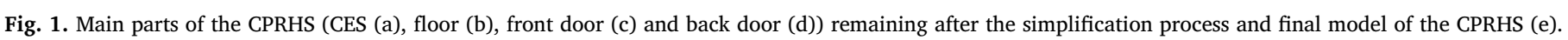


Table 3

Composition of SS316L used for dose rate estimation.

\begin{tabular}{ll}
\hline Element & Weight fraction (\%) \\
\hline $\mathrm{C}$ & 0.03 \\
$\mathrm{Cr}$ & 17.5 \\
$\mathrm{Ni}$ & 12.25 \\
$\mathrm{Mo}$ & 2.5 \\
$\mathrm{Mn}$ & 1.8 \\
$\mathrm{Si}$ & 0.5 \\
$\mathrm{P}$ & 0.025 \\
$\mathrm{~S}$ & 0.01 \\
$\mathrm{~N}$ & 0.07 \\
$\mathrm{Cu}$ & 0.3 \\
$\mathrm{Ta}$ & 0.01 \\
$\mathrm{Ti}$ & 0.1 \\
$\mathrm{~B}$ & 0.001 \\
$\mathrm{Nb}$ & 0.01 \\
$\mathrm{Co}$ & 0.05 \\
$\mathrm{Fe}$ & 64.844 \\
\hline
\end{tabular}

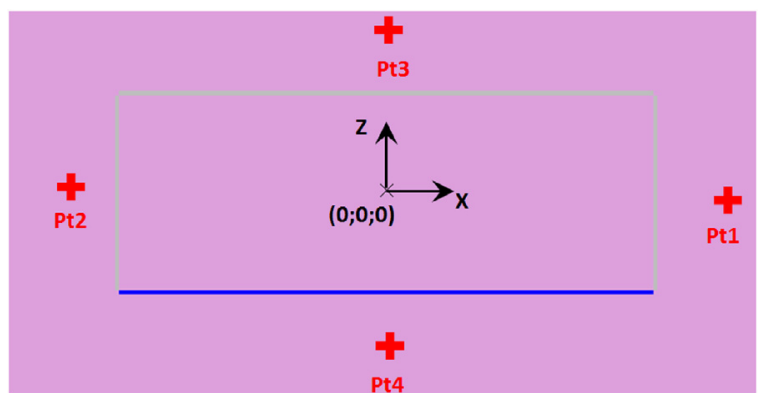

Fig. 3. Localization of the dose rate points around the CES for the $(X, Z)$ plane. Floor steel plate is represented in blue. The walls and the ceiling are represented in grey. (For interpretation of the references to colour in this figure legend, the reader is referred to the web version of the article.)

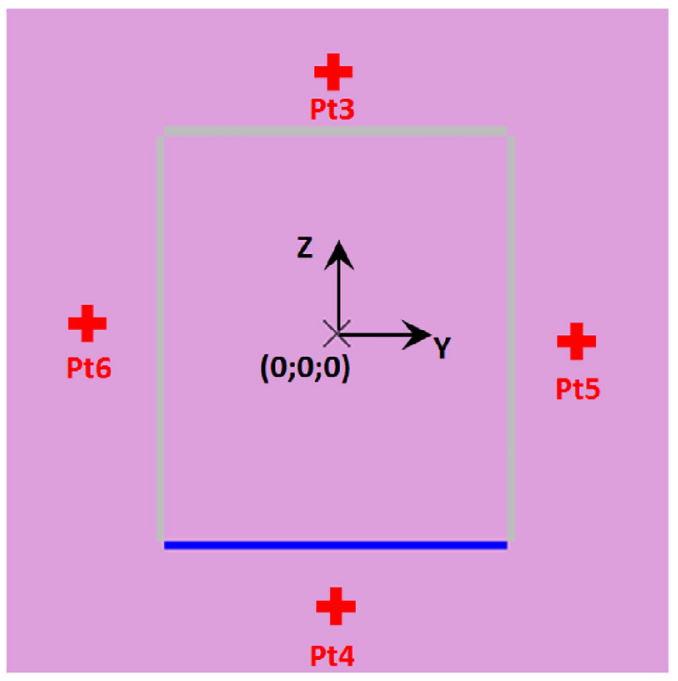

Fig. 4. Localization of the dose rate points around the CES for the $(Y, Z)$ plane. Floor steel plate is represented in blue. The walls and the ceiling are represented in grey. (For interpretation of the references to colour in this figure legend, the reader is referred to the web version of the article.)

\section{Source modeling}

\subsection{Dust composition}

Dust is formed from the interaction between the plasma, the first wall and the divertor. Dust is thus mainly composed of beryllium and tungsten coming from the erosion of the first wall and the divertor, respectively. In both cases, dust particles are activated by neutrons during the fusion reaction. Composition of activated dust has already been determined by ITER by carrying out 3D activation calculations. Many radionuclides present in the resulting dust inventory do not contribute significantly to dose rate. According to this, in analyzes that imply a release of activated dust, it is conservatively assumed that dust is $100 \%$ activated tungsten. This assumption is the most penalizing of the radiological point of view because tungsten spectra are between 10 to 100 times more penalizing in terms of dose rate and between 2 to 10 times more penalizing in terms of radiological consequences as those of beryllium dust.

The activated dust composition used in this study is the one used by ITER in their safety demonstration ([6] and references herein). It is reported in Table 1 . This inventory was obtained by ITER by carrying out 3D activation calculation with the following assumptions [7]:

- dust is mainly composed of tungsten,

- latest updates on the material and design were used,

- 3D MCNP calculations of neutron flux were performed on $8 \mathrm{~mm}$ thick divertor target following by a FISPACT activation calculation; surface tungsten removal effect $(25 \mu \mathrm{m}$ thick) was corrected by using 1D calculation,

- SA-2 scenario irradiation history was used.

\subsection{Source term determination}

Cooling down of dust spectrum was determined with DARWIN-2.3 package $[8,9]$ via the ACTIVATION scheme. PEPIN-2 depletion code was used. The nuclear data library was JEFF-3.1/A. Gamma source was determined for $1 \mathrm{~g}$ dust and for 5 cooling times ( 0 day, 12 days, 1 and 6 months, 1 year) with 24 energy groups as recommended for ITER studies (see Table 2).

\subsection{Configurations}

A parametric study has been performed to evaluate dose distributions for several configurations representative of dust contamination in the CES. Volumetric sources corresponding to possible dust contamination inside the cask were defined.

Resuspension phenomenon of dust is the first phenomenon of contamination transfer considered here. It occurs when CPRHS handles VV components or RH tools. Three configurations of the source are thus considered to take into account the behavior of the cloud of airborne dust coming from the resuspension phenomenon:

- the source is uniformly distributed on the cask floor $(950 \mathrm{~cm} \times 262 \mathrm{~cm} \times 0.1 \mathrm{~cm}$ ): as dust is mainly tungsten (a very dense material), the cloud of airborne dust will mainly fall on the CPRHS floor,

- the source is uniformly distributed on the cask ceiling $(950 \mathrm{~cm} \times 262 \mathrm{~cm} \times 0.1 \mathrm{~cm})$ : the cloud of airborne dust is capable of going on contiguous elements of the component or RH tool and some contamination of the CPRHS ceiling has to be considered,

- the source is uniformly distributed in airborne: dust remain in the form of a cloud.

Direct transfer of activated dust is involved only during direct contact. This situation occurs only once during the docking of the CPRHS to the VV. A fourth configuration was thus studied with the dust source uniformly distributed on the closure door sealing $(0.5 \mathrm{~cm}$ width and $0.1 \mathrm{~cm}$ thickness).

Dose rate level is proportional to the quantity of dust considered in the calculation. We have thus considered for each configuration a source composed of $1 \mathrm{~g}$ of dust. 

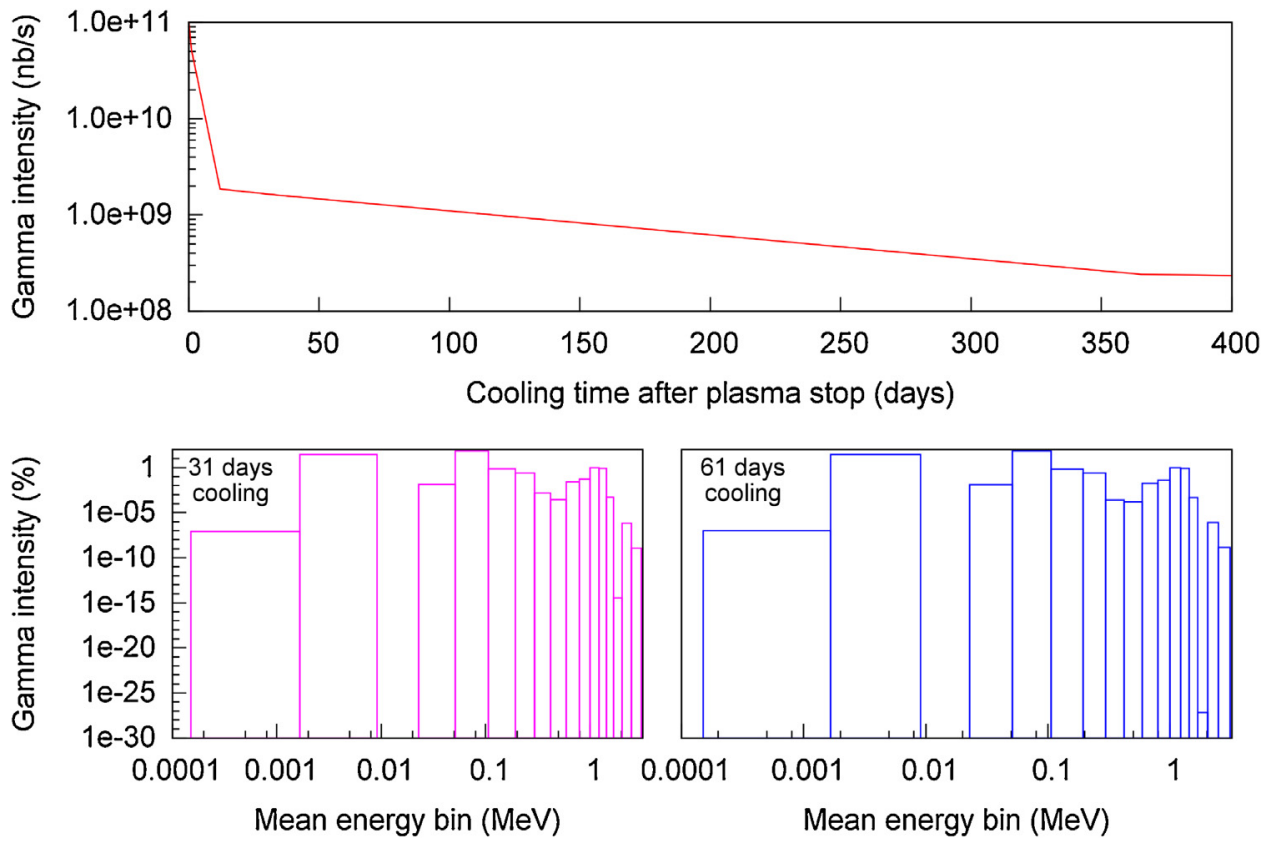

Fig. 5. Intensity of gamma spectrum for the six cooling times (up panel). Spectra obtained for 31 and 61 days cooling are also reported (left and right down panel, respectively).
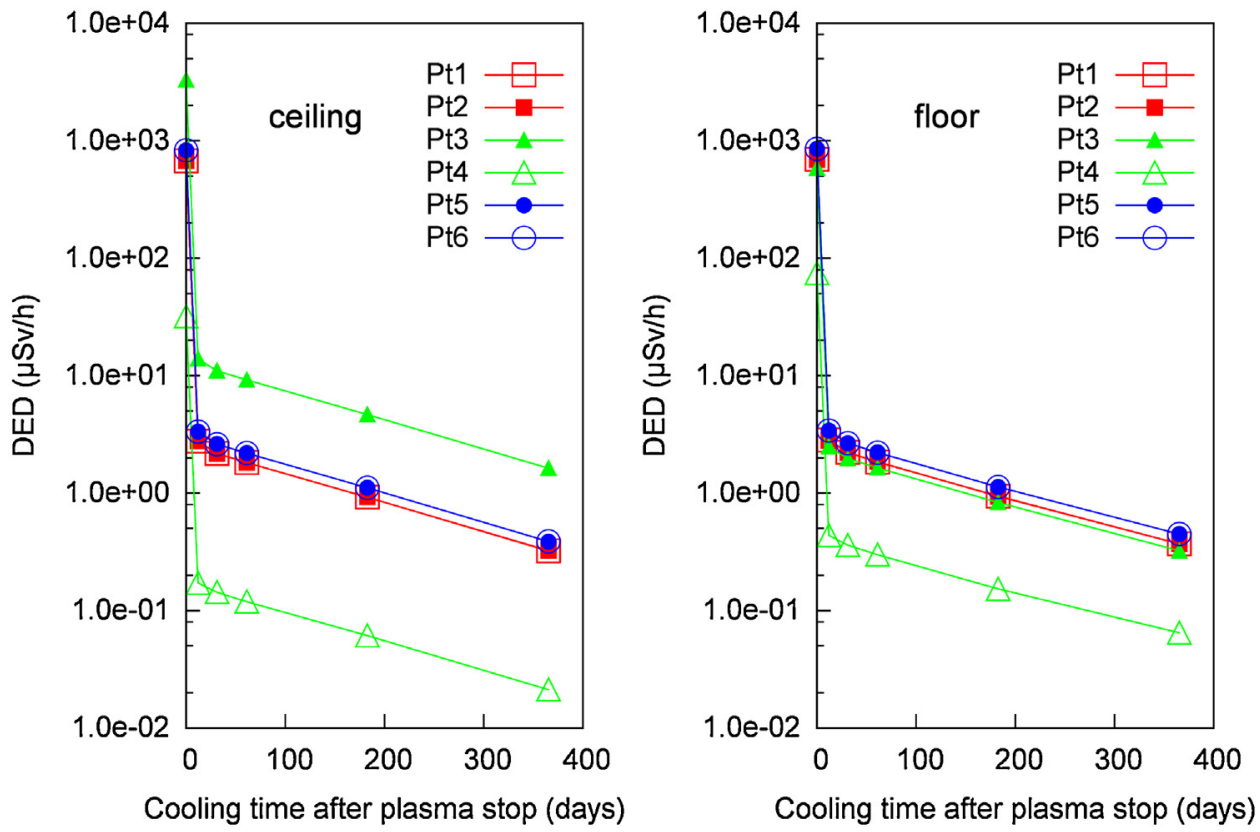

Fig. 6. Evolution of dose rate level at $30 \mathrm{~cm}$ from the CES limits with the cooling time for the floor and ceiling dust sources.

\section{Geometry and material composition of CES}

\subsection{CAD based models}

The original CAD model of the CPRHS was provided by ITER Organization. The file format is CATIA V5 and it was converted to STEP format in order to be readable both with SpaceClaim Engineer and SuperMC $[10,11]$ softwares. The analysis of the model was performed in two steps:

- CAD model simplification with the CAD computational code SpaceClaim Engineer to set the model consistent with Monte Carlo simulation geometry requirements (quadric surfaces).

The simplification has been done following some simple rules consisting in (i) removing the complex surfaces that Monte Carlo codes cannot understand in their native geometry (splines for instance), (ii) avoiding to fill gaps where neutrons could stream, (iii) removing matter and adding less possible matter when necessary at each step of the simplification. At the end of this step four main parts of the CPRHS remain (Fig. 1): the CES, the floor, the front door and its frame, the back door and its frame. CES is composed of several steel shells and so two simplified configurations were considered to determine the impact of the complex shells modelling on dose rate: SC_CAD_1 model is built from the four main parts with one shell $5 \mathrm{~mm}$ width for the CES and SC_CAD_2 model is built from the four main parts with two shells $5 \mathrm{~mm}$ width for the CES.

- CAD model translation into TRIPOLI- $4^{\circ}$ model.

Translation is assured by SuperMC code $[10,11]$. The global volume 

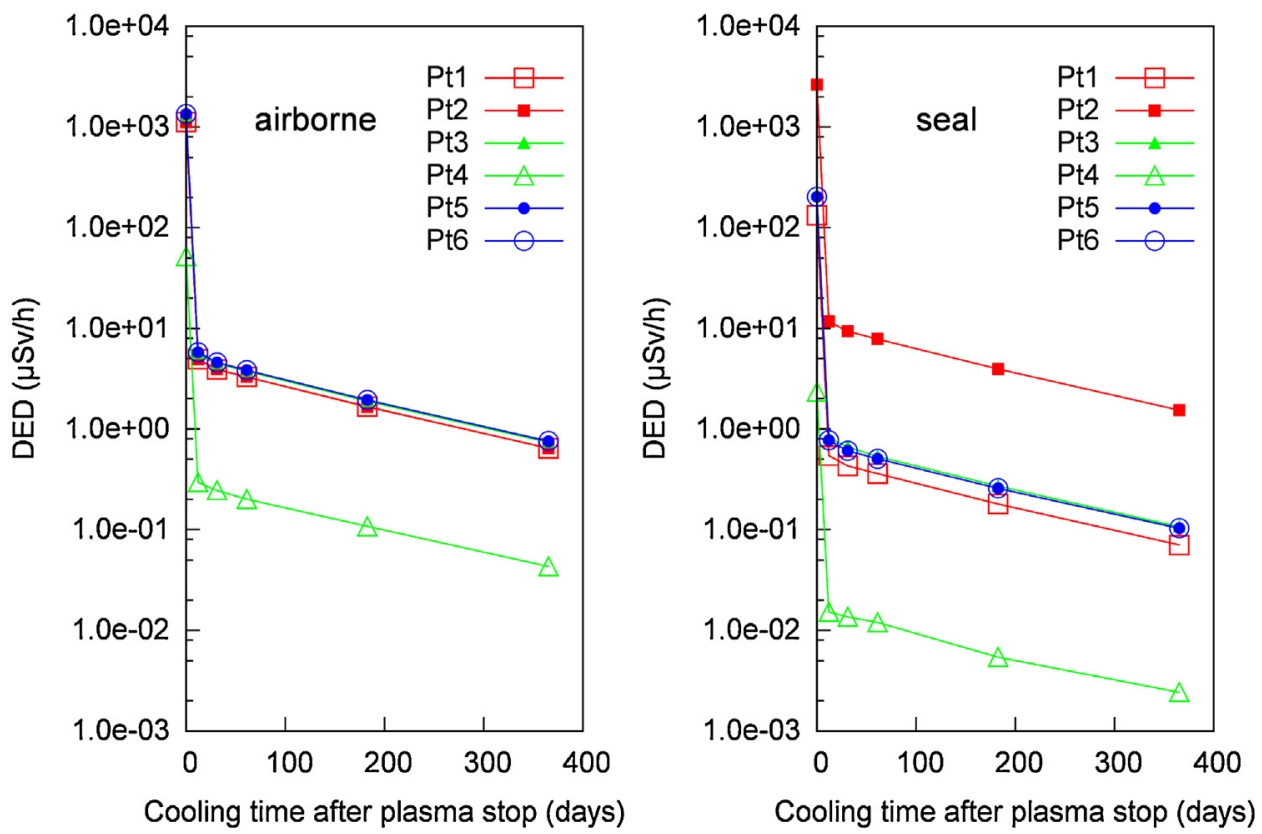

Fig. 7. Evolution of dose rate level at $30 \mathrm{~cm}$ from the CES limits with the cooling time for the seal and airborne dust sources.

Table 4

Comparison of dose rate levels obtained for the airborne source with both CAD models and the simplified TRIPOLI- $4^{\circ}$ model of the CES. Results are given in $\mu \mathrm{Sv} / \mathrm{h}$. Monte Carlo uncertainties are reported under brackets.

\begin{tabular}{|c|c|c|c|c|}
\hline \multicolumn{2}{|c|}{ Point } & \multicolumn{3}{|c|}{ Dose rate $(\mu \mathrm{Sv} / \mathrm{h})$} \\
\hline & & \multicolumn{2}{|c|}{ Simplified CAD models } & \multirow{2}{*}{$\begin{array}{l}\text { Simplified T4 mode } \\
\text { SC_T4 }\end{array}$} \\
\hline & & SC_CAD_2 & SC_CAD_1 & \\
\hline 2 & $30 \mathrm{~cm}(-X)$ & $1.70(0.26 \%)$ & $1.66(0.26 \%)$ & $3.93(0.23 \%)$ \\
\hline 1 & $30 \mathrm{~cm}(+X)$ & $2.24(0.22 \%)$ & $2.19(0.21 \%)$ & $3.90(0.20 \%)$ \\
\hline 5 & $30 \mathrm{~cm}(-Y)$ & $3.01(0.15 \%)$ & $4.33(0.12 \%)$ & $4.58(0.15 \%)$ \\
\hline 6 & $30 \mathrm{~cm}(+Y)$ & $3.00(0.16 \%)$ & $4.32(0.13 \%)$ & $4.58(0.15 \%)$ \\
\hline 4 & $30 \mathrm{~cm}(-Z)$ & $2.12(0.21 \%)$ & $2.06(0.21 \%)$ & $0.24(1.47 \%)$ \\
\hline 3 & $30 \mathrm{~cm}(+Z)$ & $3.12(0.16 \%)$ & $4.53(0.12 \%)$ & $4.48(0.24 \%)$ \\
\hline 2 & $100 \mathrm{~cm}(-X)$ & $1.03(0.18 \%)$ & $1.01(0.18 \%)$ & $2.38(0.14 \%)$ \\
\hline 1 & $100 \mathrm{~cm}(+X)$ & $1.34(0.26 \%)$ & $1.31(0.15 \%)$ & $2.37(0.14 \%)$ \\
\hline 5 & $100 \mathrm{~cm}(-Y)$ & $1.99(0.11 \%)$ & $2.78(0.09 \%)$ & $3.14(0.13 \%)$ \\
\hline 6 & $100 \mathrm{~cm}(+Y)$ & $1.99(0.11 \%)$ & $2.77(0.09 \%)$ & $3.14(0.11 \%)$ \\
\hline 4 & $100 \mathrm{~cm}(-Z)$ & $1.42(0.13 \%)$ & $1.38(0.13 \%)$ & $0.20(0.78 \%)$ \\
\hline 3 & $100 \mathrm{~cm}(+Z)$ & $2.06(0.11 \%)$ & $2.90(0.08 \%)$ & $3.00(0.13 \%)$ \\
\hline 0 & Cask center & $23.08(1.93 \%)$ & $21.91(0.35 \%)$ & $21.67(0.59 \%)$ \\
\hline
\end{tabular}

and mass have been preserved during this conversion to TRIPOLI-4 ${ }^{\oplus}$ geometry process. A final view of the lower part of the CPRHS is reported in Fig. 2.

\subsection{Simplified TRIPOLI-4 model}

A simplified CES geometry (named SC_T4 configuration in the following) based on the one reported in [5] was used to perform the calculation. The dimensions measured in the simplified CAD based models were used in the SC_T4 configuration. The CES floor was thus represented by a $850 \mathrm{~cm} \times 262 \mathrm{~cm} \times 7 \mathrm{~cm}$ steel plate. The envelope and the lateral doors were represented by $5 \mathrm{~mm}$ steel thickness which is the thickness envisaged for confinement.

\subsection{Comparison of models}

For all models, the material is Stainless Steel $316 \mathrm{~L}$ which composition is summarized in Table 3. The comparison between both simplified models and SC_T4 configuration was performed for the 31 days
Table 5

Comparison of dose rate levels obtained for the floor source with both CAD models and the simplified TRIPOLI- $4^{\circ}$ model of the CES. Results are given in $\mu \mathrm{Sv} / \mathrm{h}$. Monte Carlo uncertainties are reported under brackets.

\begin{tabular}{|c|c|c|c|c|}
\hline \multicolumn{2}{|c|}{ Point } & \multicolumn{3}{|c|}{ Dose rate $(\mu \mathrm{Sv} / \mathrm{h})$} \\
\hline & & \multicolumn{2}{|c|}{ Simplified CAD models } & \multirow{2}{*}{$\begin{array}{l}\text { Simplified T4 model } \\
\text { SC_T4 }\end{array}$} \\
\hline & & SC_CAD_2 & SC_CAD_1 & \\
\hline 2 & $30 \mathrm{~cm}(-X)$ & $0.31(0.47 \%)$ & $0.31(0.48 \%)$ & $2.21(0.20 \%)$ \\
\hline 1 & $30 \mathrm{~cm}(+X)$ & $0.49(0.35 \%)$ & $0.48(0.36 \%)$ & $2.23(0.20 \%)$ \\
\hline 5 & $30 \mathrm{~cm}(-Y)$ & $0.36(0.34 \%)$ & $0.49(0.25 \%)$ & $2.67(0.14 \%)$ \\
\hline 6 & $30 \mathrm{~cm}(+Y)$ & $0.36(0.35 \%)$ & $0.48(0.25 \%)$ & $2.67(0.14 \%)$ \\
\hline 4 & $30 \mathrm{~cm}(-Z)$ & $14.80(0.13 \%)$ & $14.78(0.13 \%)$ & $0.36(1.09 \%)$ \\
\hline 3 & $30 \mathrm{~cm}(+Z)$ & $0.70(0.31 \%)$ & $0.91(0.18 \%)$ & $1.97(0.23 \%)$ \\
\hline 2 & $100 \mathrm{~cm}(-X)$ & $0.23(0.32 \%)$ & $0.22(0.31 \%)$ & $1.71(0.15 \%)$ \\
\hline 1 & $100 \mathrm{~cm}(+X)$ & $0.33(0.51 \%)$ & $0.32(0.26 \%)$ & $1.72(0.16 \%)$ \\
\hline 5 & $100 \mathrm{~cm}(-Y)$ & $0.14(0.38 \%)$ & $0.18(0.32 \%)$ & $2.32(0.16 \%)$ \\
\hline 6 & $100 \mathrm{~cm}(+Y)$ & $0.14(1.06 \%)$ & $0.17(0.32 \%)$ & $2.31(0.11 \%)$ \\
\hline 4 & $100 \mathrm{~cm}(-Z)$ & $8.24(0.07 \%)$ & $8.23(0.07 \%)$ & $0.31(0.52 \%)$ \\
\hline 3 & $100 \mathrm{~cm}(+Z)$ & $0.50(0.19 \%)$ & $0.64(0.14 \%)$ & $1.48(0.15 \%)$ \\
\hline 0 & Cask center & $2.93(0.08 \%)$ & $2.91(0.08 \%)$ & $9.10(0.06 \%)$ \\
\hline
\end{tabular}

cooling time source. The CES was modeled without any RH tool inside. In a first approximation, we neglected activity release due to RH tools and considered only activity due to dust remained in the CES. As RH tools may induce shielding protection, this assumption can be considered as conservative.

\section{Dose rate calculations and analysis}

\subsection{Dose rate estimation}

TRIPOLI- $4.10^{\circ}$ [12] was used with EPDL-97 library to determine the dose rate level for the different configurations. The gamma sources determined with DARWIN at the several cooling times were used as input data. The DOSE_H*(10) predefined TRIPOLI- $4{ }^{\circ}$ score follows ICRP-74 recommendations [13] for dose rate calculations. It was used here to determine the dose rate level at $30 \mathrm{~cm}$ and $100 \mathrm{~cm}$ from the CES exterior limits. Score points are detailed in Figs. 3 and 4 . In addition, dose rate maps were also estimated: 
Table 6

Comparison of dose rate levels obtained for the ceiling source with both CAD models and the simplified TRIPOLI- $4^{\circ}$ model of the CES. Results are given in $\mu \mathrm{Sv} / \mathrm{h}$. Monte Carlo uncertainties are reported under brackets.

\begin{tabular}{|c|c|c|c|c|}
\hline \multicolumn{2}{|c|}{ Point } & \multicolumn{3}{|c|}{ Dose rate $(\mu \mathrm{Sv} / \mathrm{h})$} \\
\hline & & \multicolumn{2}{|c|}{ Simplified CAD models } & \multirow{2}{*}{$\begin{array}{l}\text { Simplified T4 mode } \\
\text { SC_T4 }\end{array}$} \\
\hline & & SC_CAD_2 & SC_CAD_1 & \\
\hline 2 & $30 \mathrm{~cm}(-X)$ & $0.90(0.28 \%)$ & $0.85(0.31 \%)$ & $2.17(0.12 \%)$ \\
\hline 1 & $30 \mathrm{~cm}(+X)$ & $1.16(0.23 \%)$ & $1.09(0.23 \%)$ & $2.18(0.13 \%)$ \\
\hline 5 & $30 \mathrm{~cm}(-Y)$ & $1.47(0.18 \%)$ & $1.90(0.14 \%)$ & $2.61(0.09 \%)$ \\
\hline 6 & $30 \mathrm{~cm}(+Y)$ & $1.48(0.17 \%)$ & $1.90(0.14 \%)$ & $2.62(0.08 \%)$ \\
\hline 4 & $30 \mathrm{~cm}(-Z)$ & $1.08(0.17 \%)$ & $1.04(0.17 \%)$ & $0.14(1.16 \%)$ \\
\hline 3 & $30 \mathrm{~cm}(+Z)$ & $7.40(0.17 \%)$ & $11.77(0.15 \%)$ & $11.01(0.11 \%)$ \\
\hline 2 & $100 \mathrm{~cm}(-X)$ & $0.70(0.18 \%)$ & $0.66(0.43 \%)$ & $1.68(0.09 \%)$ \\
\hline 1 & $100 \mathrm{~cm}(+X)$ & $0.87(0.18 \%)$ & $0.81(0.16 \%)$ & $1.69(0.10 \%)$ \\
\hline 5 & $100 \mathrm{~cm}(-Y)$ & $1.50(0.10 \%)$ & $2.04(0.08 \%)$ & $2.27(0.07 \%)$ \\
\hline 6 & $100 \mathrm{~cm}(+Y)$ & $1.50(0.10 \%)$ & $2.04(0.08 \%)$ & $2.27(0.06 \%)$ \\
\hline 4 & $100 \mathrm{~cm}(-Z)$ & $0.68(0.16 \%)$ & $0.65(0.45 \%)$ & $0.11(0.62 \%)$ \\
\hline 3 & $100 \mathrm{~cm}(+Z)$ & $4.71(0.11 \%)$ & $6.95(0.08 \%)$ & $6.76(0.06 \%)$ \\
\hline 0 & Cask center & $9.77(0.04 \%)$ & $9.14(0.04 \%)$ & $8.93(0.04 \%)$ \\
\hline
\end{tabular}

- inside the CES for $4 \mathrm{~mm} \times 4 \mathrm{~mm} \times 4 \mathrm{~mm}$ bins,

- around the CES for $6 \mathrm{~mm} \times 6 \mathrm{~mm} \times 6 \mathrm{~mm}$ bins.

\subsection{Dose rate levels obtained with the SC_T4 geometry}

Calculations were performed at each cooling times with the source intensities reported in Fig. 5. Maintenance is assumed to begin after Tokamak ventilation which is estimated at 4 weeks, thus spectra obtained at 31 and 61 days cooling are also plotted. According to the spectra reported in Fig. 5, the choice of this date induces no consequence on the dose rate estimation, the spectra obtained at 31 and 61 days being very close. We have thus fixed in the following the beginning of the maintenance operations 31 days after the plasma shutdown.

Dose rate levels obtained with the SC_T4 geometry at $30 \mathrm{~cm}$ from CES for the four source configurations are reported in Figs. 6 and 7 . Dose rate levels decrease exponentially with cooling time as expected. Symmetrical points lead to the same dose rate value (Pt1 and Pt2, Pt5 and Pt6) except Pt4 which leads to a smaller estimation than Pt3 due to the $7 \mathrm{~cm}$ width steel plate positioned on the CES floor. 31 days after plasma shut-down, maximal dose rate varies between 2.67 and $11 \mu \mathrm{Sv} /$ $\mathrm{h}$ at $30 \mathrm{~cm}$ from the CES exterior limits.

\subsection{Validation of the SC_T4 geometry}

CES is composed of several steel shells. So two simplified CAD configurations, SC_CAD_1 and SC_CAD_2, were considered here to determine the impact of the complex shells modelling and to check the conservatism of the SC_T4 configuration. The main differences between the CAD models and the TRIPOLI- $4^{\circ}$ geometry are thus the CES and doors modelling. In the SC_T4 model the door is $5 \mathrm{~mm}$ width and in the CAD converted models, the door width is between 15 and $21 \mathrm{~mm}$. Moreover, in the TRIPOLI- $4^{\circ}$ model, the floor is a $7 \mathrm{~cm}$ width plate whereas in the CAD models it is a complex assembly of different components.

Results obtained at 30 and $100 \mathrm{~cm}$ from the CES limits and with both CAD models were compared with the dose rate estimation obtained with the SC_T4 geometry.

These values are reported in Table 4 for the airborne source. For Pt1 and Pt2, the discrepancies can be explained by the width of the doors. For Pt5, Pt6 and Pt3, results are consistent: SC_T4 model overestimates CAD simplified models. For Pt4, the models differ too much to compare the results. As the point is in the axis of the CES, and as the floor is thinner at this point in the simplified CAD models, gamma are not stopped and dose rate is higher. The results for the point in the center of the CES (Point 0 ) are very consistent.

The comparison of results reported in Table 5 for the floor source is very difficult. Actually, two phenomena occur: the source location is not the same, and the particle transport is different because of the floor configuration. The highest discrepancy is observed for the Pt4 where the gamma source is less attenuated in the simplified CAD models and for the center point where, on the contrary, more attenuation occurs because of matter between the bottom of the floor and the calculation point.

For the ceiling source (Table 6), except for the Pt4, results are very consistent.

To conclude results obtained with the simplified CAD models and SC_T4 geometry are consistent and TRIPOLI- $4^{\circ}$ modelling leads to conservative dose rate values.

\subsection{Dose rate maps}

It was estimated by ITER that the maintenance will begin at least one month after the shutdown. Dose rate maps have thus been estimated for a 31 days cooling. They are reported in Figs. 8-12. The seal source is the most critical configuration in terms of dose rate levels, especially if hands-on operations are needed near or in the CES. Actually, the seal source is locally more concentrated for $1 \mathrm{~g}$ dust due to the geometry of the seal and leads to the highest dose rate values.

\section{Discussion}

If CES needs to be maintained or repaired, regulatory requirements and ALARA objectives have to be respected in terms of workers exposure. During such operation, it is assumed that operators will be equipped with ventilated air suit and will be on pseudo-contact with dust. ITER individual exposure limits are set at $100 \mu \mathrm{Sv} / \mathrm{h}$ which is the

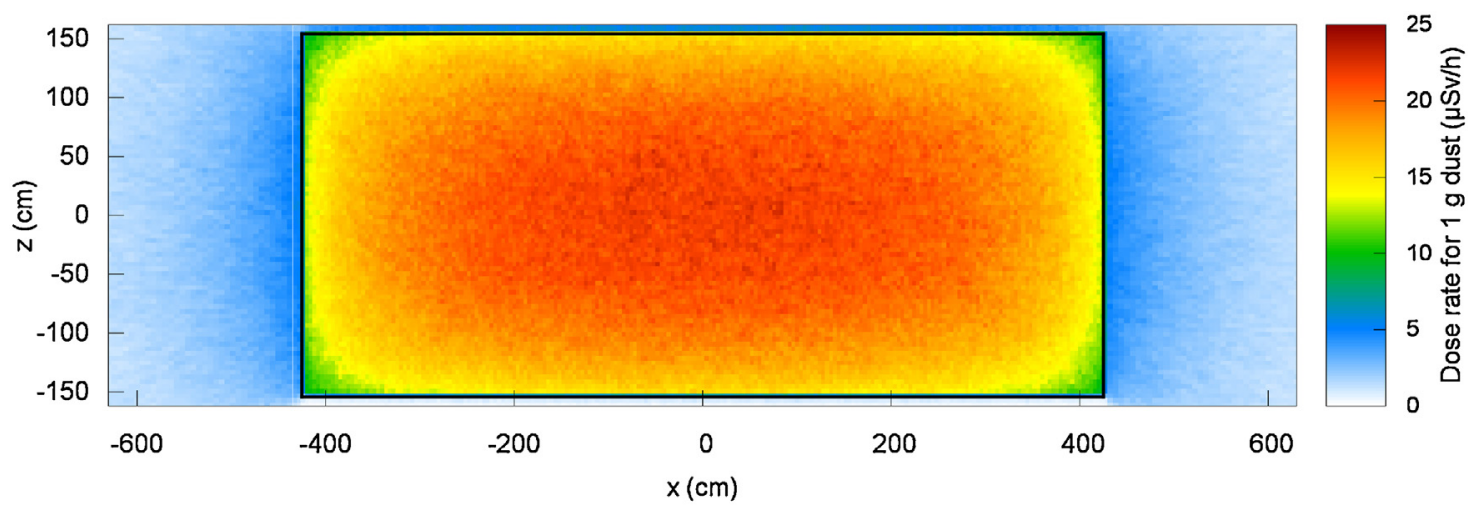

Fig. 8. Dose rate map obtained for the airborne source and with $y=0 \mathrm{~cm}$. CES limits are represented in black. 


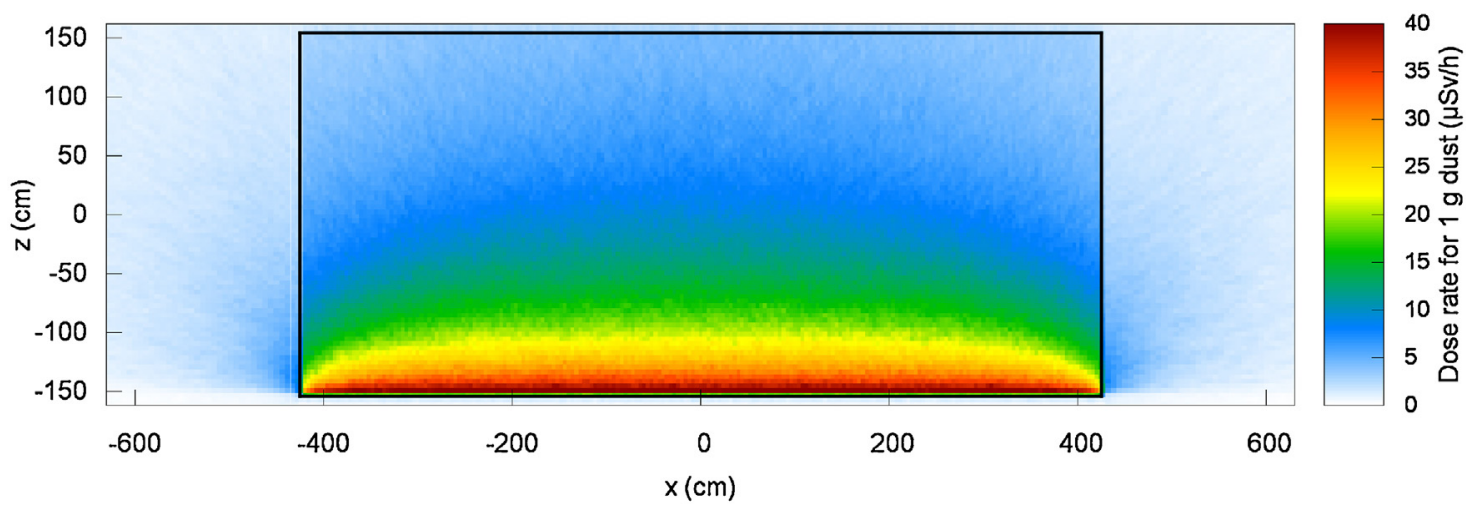

Fig. 9. Dose rate map obtained for the floor source and with $y=0 \mathrm{~cm}$. CES limits are represented in black.

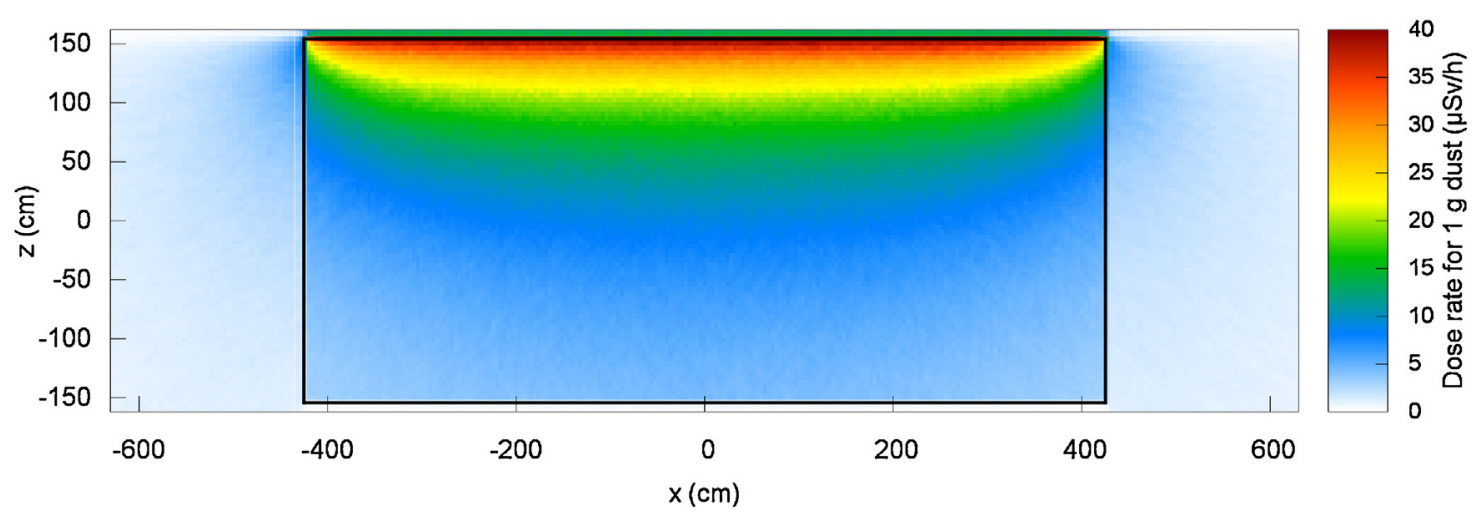

Fig. 10. Dose rate map obtained for the ceiling source and with $y=0 \mathrm{~cm}$. CES limits are represented in black.

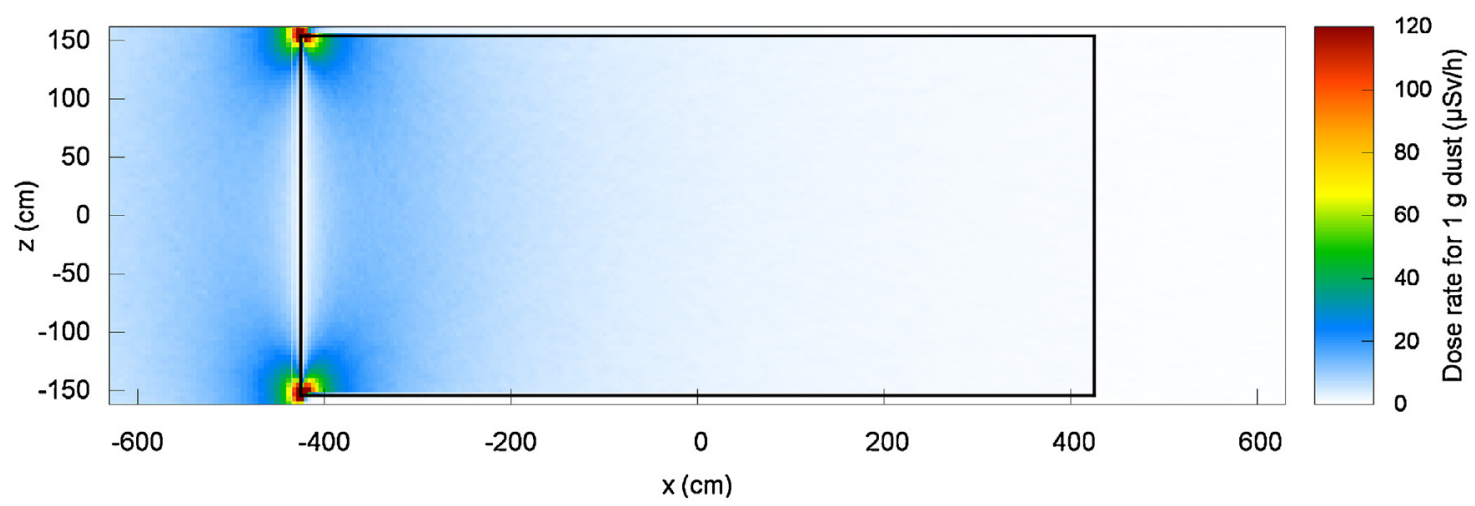

Fig. 11. Dose rate map obtained for the seal source and with $y=0 \mathrm{~cm}$. CES limits are represented in black.

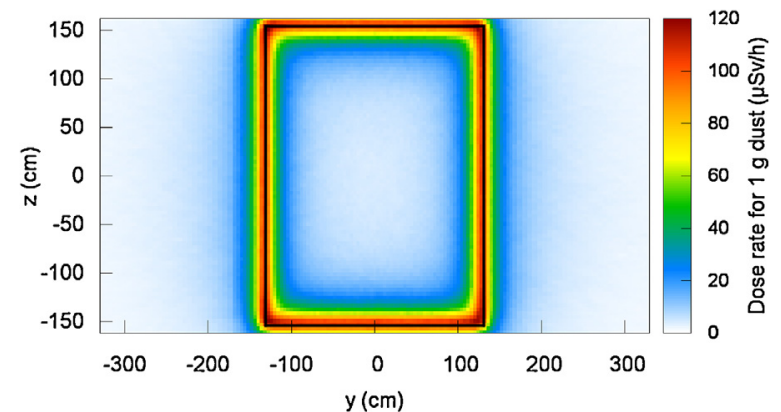

Fig. 12. Dose rate map obtained for the seal source and with $x=-432 \mathrm{~cm}$ (closure door localization). CES limits are represented in black. upper limit of dose on contact for hands-on maintenance. The acceptable limit to reach will be fixed by the collective doses due to hands-on maintenance and fixed at $0.5 \mathrm{p} . \mathrm{Sv} / \mathrm{y}$. Dose optimizations provisions have to be implemented to reduce these doses As Low As Reasonably Achievable (ALARA) [14]. The value considered in this study is thus $5 \mu \mathrm{Sv} / \mathrm{h}[15]$.

To illustrate the possible use of the dosimetric data obtained in this study, the definition of a decontamination level and maintenance plan, we have considered a complex dust source composed of:

- $1 \%$ contamination on the ceiling,

- $84 \%$ contamination on the floor,

- $5 \%$ contamination in the CES airborne,

- $10 \%$ contamination on the closure door sealing.

The dust spectrum obtained for a 31 days cooling is considered here. 


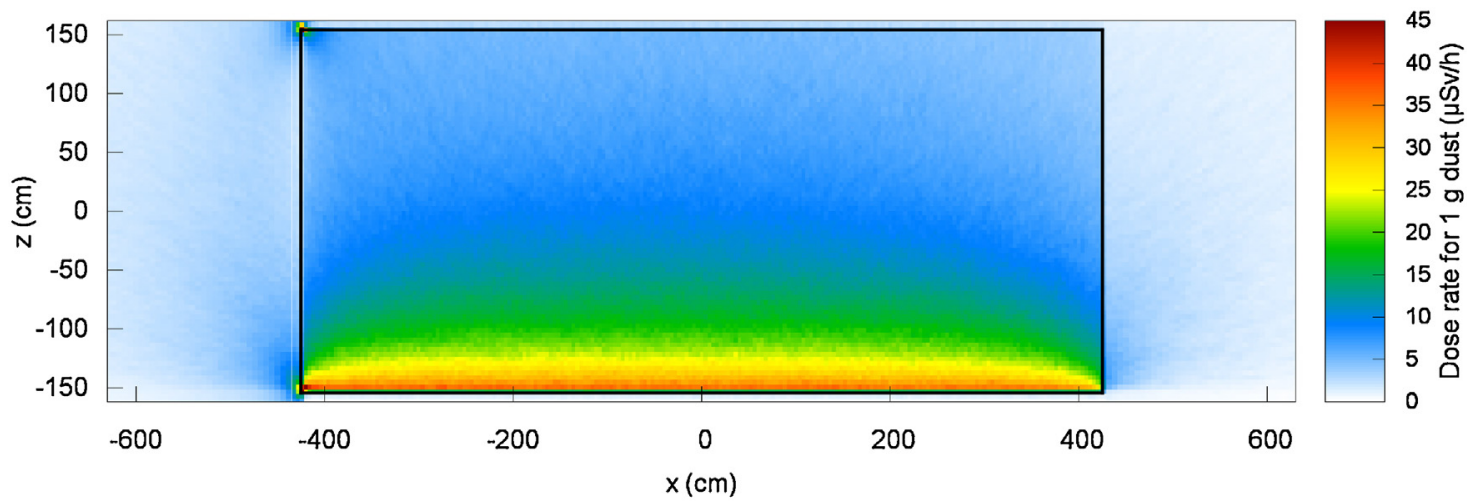

Fig. 13. Dose rate map obtained for the mixed source by the combination of the other maps and for $y=0 \mathrm{~cm}$. CES limits are represented in black.

Table 7

Comparison of dose rate levels obtained with a combination of the data base results and with a full Monte Carlo simulation. Results are given in $\mu \mathrm{Sv} / \mathrm{h}$. Monte Carlo and propagated uncertainties are reported under brackets.

\begin{tabular}{|c|c|c|c|c|}
\hline \multicolumn{2}{|c|}{ Point } & \multicolumn{2}{|c|}{ Dose rate $(\mu \mathrm{Sv} / \mathrm{h})$} & \multirow[t]{2}{*}{ Deviation (\%) } \\
\hline & & DDB mixed & Full Monte Carlo & \\
\hline 1 & $30 \mathrm{~cm}(+X)$ & $2.129(0.45 \%)$ & $2.127(0.33 \%)$ & -0.09 \\
\hline 2 & $30 \mathrm{~cm}(-X)$ & $3.010(0.32 \%)$ & $3.018(0.24 \%)$ & 0.27 \\
\hline 3 & $30 \mathrm{~cm}(+Z)$ & $2.055(0.47 \%)$ & $2.054(0.33 \%)$ & -0.07 \\
\hline 4 & $30 \mathrm{~cm}(-Z)$ & $0.318(3.03 \%)$ & $0.327(1.77 \%)$ & 2.83 \\
\hline 5 & $30 \mathrm{~cm}(+Y)$ & $2.556(0.38 \%)$ & $2.553(0.21 \%)$ & -0.15 \\
\hline 6 & $30 \mathrm{~cm}(-Y)$ & $2.558(0.38 \%)$ & $2.556(0.21 \%)$ & -0.04 \\
\hline 1 & $100 \mathrm{~cm}(+X)$ & $1.612(0.60 \%)$ & $1.605(0.22 \%)$ & -0.42 \\
\hline 2 & $100 \mathrm{~cm}(-X)$ & $2.587(0.37 \%)$ & $2.592(0.19 \%)$ & 0.22 \\
\hline 3 & $100 \mathrm{~cm}(+Z)$ & $1.531(0.63 \%)$ & $1.527(0.20 \%)$ & -0.25 \\
\hline 4 & $100 \mathrm{~cm}(-Z)$ & $0.273(3.52 \%)$ & $0.276(0.79 \%)$ & 1.06 \\
\hline 5 & $100 \mathrm{~cm}(+Y)$ & $2.195(0.44 \%)$ & $2.190(0.16 \%)$ & -0.23 \\
\hline 6 & $100 \mathrm{~cm}(-Y)$ & $2.198(0.44 \%)$ & $2.188(0.16 \%)$ & -0.46 \\
\hline
\end{tabular}

A dose rate map was obtained by summing the single dose maps, according to their respective contributions. Results are reported in Fig. 13. The distribution is close to the one obtained for the floor source, except hot spots (about $68 \mu \mathrm{Sv} / \mathrm{h}$ ) localized at the sealing. Associated Monte Carlo uncertainties were also propagated. Besides, the complex source configuration was inserted in a full Monte Carlo simulation and results were compared with DDB results in Table 7. Deviations between DDB mixed results and Monte Carlo simulations are less than 1\% except for Pt4 due to the presence of the steel plate. DDB results can thus be used to determine dose rate levels for complex sources described by a mix of the configurations studied here.

According to the maximal dose rate considered here, $5 \mu \mathrm{Sv} / \mathrm{h}$, we have also determined the associated maximal dust mass obtained 31 days after the plasma shut-down for this source configuration. DDB mixed results obtained for points localized at $30 \mathrm{~cm}$ for the CES limits were used. According to the dose rate limit considered here $(5 \mu \mathrm{Sv} / \mathrm{h})$, dust mass varies between 1.66 and $2.43 \mathrm{~g}$ when Pt4 is neglected. Dust removal techniques with a high efficiency have thus to be chosen in order to allow hands-on operations near or in the cask. A 60-s vacuum cleaning and an additional 60-s brushing and vacuum cleaning of the CES could lead to trace amount of dust about $7.8 \times 10^{-10} \mathrm{~g} / \mathrm{mm}^{2}[6]$. If the design chosen for the CES and the sealing allow the use of such techniques, dust could be able to be removed to that amount.

\section{Conclusion}

In this study, dose rate estimations due to remained dust in the CES were carried out inside and outside the CES. The simplified model of the CES has been validated against CAD based models and could be used for further studies. Four uniformized source configurations were considered: ceiling, floor, airborne and closure door seal. TRIPOLI-4.10 code and DARWIN 2.3 package were used simultaneously to determine a dosimetric data base of dose rate levels inside and outside CES. It has been shown that dose rate levels stored in the DDB could further be used to determine dose rate maps of complex source configurations based on the four source configurations used in this study. The results obtained for the complex source configuration show that a small amount of dust released into the CES could lead to non-negligeable dose rates. Data reported in the DDB provides thus a basis for further developments of the ITER maintenance operations.

\section{Acknowledgments}

This work was funding by ITER Organization in the framework of Site Support Agreement 57: Transfer Cask and Decontamination Hot Cell.

The authors would like to express their appreciation to Jean-Pierre Martins for his technical support on CPRHS design.

The views and opinions expressed herein do not necessarily reflect those of the ITER Organization.

Table 8

Weight breakdown comparison to validate the model after the simplification process.

\begin{tabular}{|c|c|c|c|}
\hline Component & $\begin{array}{l}\text { Reference weight } \\
\text { (tons) }\end{array}$ & $\begin{array}{l}\text { Final CAD model } \\
\text { (tons) }\end{array}$ & Deviation (tons) \\
\hline Cask floor & 18 & 18.6 & +0.6 \\
\hline Cask envelope & 11.5 & 5.5 & -6.0 \\
\hline Cask rear door & 2.5 & 5.0 & +2.5 \\
\hline Double door & 5 & 2.4 & -2.6 \\
\hline Tractor system & 10 & - & -10 \\
\hline Plug rails & 5 & - & -5.0 \\
\hline Total & 52 & 31.5 & -20.5 \\
\hline
\end{tabular}


Table 9

Volume breakdown comparison to validate the model after the translation process.

\begin{tabular}{llcl}
\hline Component & SpaceClaim $\left(\mathrm{m}^{3}\right)$ & TRIPOLI-4 $\left(\mathrm{m}^{3}\right)$ & Ratio T4/SC \\
\hline Cask floor & 2.380 & 2.380 & 1.000 \\
Cask envelope & 0.706 & 0.710 & 1.005 \\
Cask rear door & 0.642 & 0.641 & 0.999 \\
Double door & 0.307 & 404 & 0.990 \\
Total & 4.036 & 4.035 & 1.000 \\
\hline
\end{tabular}

\section{Appendix A. Simplication of the CAD geometry}

The first step in the simplification consisted in sorting the different components in the full model: Transfer Cask support, Transfer Cask rails, Port Plug inside Cask, Transfer Cask, and the Tractors inside Cask. Some parts in the Transfer Cask have been removed in order both to allow the conversion into TRIPOLI- $4^{\circ}$ format data file and to have a simpler model for analysis. The removed parts are: the wheels, the very little elements making the Transfer Cask (like screws, cables, pulleys, bolts), parts of the plug rails and parts of the floor. At the end, the four main parts of the Transfer Cask remain: the Envelope, the Floor, the Front Door and its frame, the Back Door and its frame. Some basic checks have been performed to assure that the simple model was consistent with the initial model. The stainless steel global weight and the breakdown of this weight were compared with the weight of the four components in Table 8.

Reference weights were taken from reference [16]. The removed part of the floor, the wheels and the removed part of the Plug Rails contribute to 5.9 tons to the final CAD model weight. Tractor is still about 10 tons and the expected total weight of the final simplified model is about $31.5+5.9+10=47.4$ tons. Compared to 52 tons in the original full model, these conclusions can be drawn: simple model total weight is lower than initial total weight and for neutronics, the model is conservative (less matter induce less shielding if gaps have not been filled); total weight for the simple model and the initial model are consistent.

The second step in the simplification process is the translation of the simplified CAD model to TRIPOLI- $4^{\circ}$. This phase was performed with SuperMC code $[10,11]$. The translation was validated by comparing volumes (Table 9).

The global volume and mass have been preserved during this conversion to TRIPOLI- $4^{\circ}$ geometry process. Some discrepancy can be observed on the envelope but $0.5 \%$ can be considered as negligible for the current study.

\section{References}

[1] D. Locke, et al., Transfer cask system design activities: status and plan, Fusion Eng. Des. 86 (2011) 2101-2104, http://dx.doi.org/10.1016/j.fusengdes.2011.03.097.

[2] A. Tesini, J. Palmer, The ITER remote maintenance system, Fusion Eng. Des. 83 (2008) 810-816, http://dx.doi.org/10.1016/j.fusengdes.2008.08.011.

[3] D. Locke, et al., Progress in conceptual design of the ITER cask and plug remote handling system, Fusion Eng. Des. 89 (2014) 2419-2424, http://dx.doi.org/10. 1016/j.fusengdes.2013.12.022.

[4] J. Martins, et al., Cask and plug handling system design port cell, Fusion Eng. Des. 86 (2011) 1886-1889, http://dx.doi.org/10.1016/j.fusengdes.2011.03.025.

[5] H. Liu, et al., Application of the R2Smesh approach for the accurate estimation of photon radiation dose fields around activated ITER in-vessel components, Fusion Eng. Des. 98-99 (2015) 2187-2190, http://dx.doi.org/10.1016/j.fusengdes.2015. 04.067.

[6] M. Saito, et al., Preliminary assessment for dust contamination of ITER in-vessel transporter, Fusion Eng. Des. 89 (2014) 2352-2356, http://dx.doi.org/10.1016/j. fusengdes.2014.02.023.

[7] S. Rosanvallon, et al., Waste management plans for ITER, Fusion Eng. Des. 109-111 (2016) 1442-1446, http://dx.doi.org/10.1016/j.fusengdes.2015.12.002.

[8] A. Tsilanizara, et al., DARWIN: an evolution code system for a large range of applications, J. Nucl. Sci. Technol. 37 (2000) 845-849, http://dx.doi.org/10.1080/
00223131.2000 .10875009$.

[9] L. San Felice, et al., Experimental validation of the DARWIN 2.3 package for fuel cycle applications, Nucl. Technol. 184 (2013) 217-232, http://dx.doi.org/10. 13182/NT12-121.

[10] Y. Wu, et al., CAD based Monte Carlo program for integrated simulation of nuclear system SuperMC, Ann. Nucl. 82 (2015) 161-168, http://dx.doi.org/10.1016/j. anucene.2014.08.058.

[11] Y. Wu, F. team, CAD based interface programs for fusion neutron transport simulation, Fusion Eng. Des. 84 (2009) 1987-1992, http://dx.doi.org/10.1016/j. fusengdes.2008.12.041.

[12] E. Brun, et al., TRIPOLI-4 R CEA, EDF and AREVA reference Monte Carlo code, Ann. Nucl. Energy 82 (2015) 151-160, http://dx.doi.org/10.1016/j.anucene.2014.07. 053.

[13] International Commission on Radiological Protection, Conversion Coefficients for Use in Radiological Protection Against External Radiation, ICRP Publication 74, 2016.

[14] P. Cortes, et al., Optimization of the design phase of the potential impact of ITER on workers, the public and the environment, Fusion Eng. Des. 85 (2010) 2263-2267, http://dx.doi.org/10.1016/j.fusengdes.2010.09.004.

[15] M. Saito, et al., Decontamination assessment for ITER blanket remote handling system, Proceedings of PLASMA2014 (Nigata, Japan, Nov. 2014) 20PB-10 (2014).

[16] C. Andrada, 23.03-B.01 Report, ITER D PR837S v1.0. 